\title{
Accounting for International War: The State of the Discipline
}

\author{
J. DAVID SINGER* \\ University of Michigan
}

\begin{abstract}
In studies of war it is important to observe that the processes leading to so frequent an event as conflict are not necessarily those that lead to so infrequent an event as war. Also, many models fail to recognize that a phenomenon irregularly distributed in time and space, such as war, cannot be explained on the basis of relatively invariant phenomena. Much research on periodicity in the occurrence of war has yielded little result, suggesting that the direction should now be to focus on such variables as diffusion and contagion. Structural variables, such as bipolarity, show contradictory results with some clear inter-century differences. Bipolarity, some results suggest, might have different effects on different social entities. A considerable number of studies analysing dyadic variables show a clear connection between equal capabilities among contending nations and escalation of conflict into war. Finally, research into national attributes often points to strength and geographical location as important variables. In general, the article concludes, there is room for modest optimism, as research into the question of war is no longer moving in non-cumulative circles. Systematic research is producing results and there is even a discernible tendency of convergence, in spite of a great diversity in theoretical orientations.
\end{abstract}

In the early 1930s, when Quincy Wright in America and Lewis Richardson in England began their respective investigations into the causes of war, they were not only unaware of one another's work; they were, of necessity, equally unaware of the radical change that their studies would produce in the field of war and peace research. With perhaps the exception of Jean de Bloch - whose Future of War (1899) sought all too successfully to predict what warfare would look like on the basis of a systematic examination of previous wars - and Pitirim Sorokin (1937) - whose focus was on the relationship between long cycles in cultural patterns and fluctuations in war and revolution over several thousand years - Wright (1942) and Richardson (1941 and 1960a, b) mark the first traceable efforts to bring scientific method to bear on international conflict. While physical phenomena had been studied in an essentially

* I am indebted to Michael Champion, Peter Wallensteen, and Klaus Jürgen Gantzel for assistance in preparing this essay, and to The National Science Foundation for support of much of the research reported here. An abridged version will appear in the Annual Review of Sociology. scientific fashion for several centuries, and biological phenomena for nearly a century, social phenomena had remained largely the domain of theological speculation, moral imperative, and conventional folklore. But even as economics and sociology began to emerge as systematic sciences, followed in due course by the study of national political systems, international politics remained one of the most backward of disciplines.

This state of affairs was, and often still is, explained in terms of the intractability of the material; not only does much of the behavior occur in secret, but the material, structural, and cultural conditions associated with the international system are allegedly too spread out in time and in space to permit direct observation. But that explanation is incomplete. Political elites, it can be assumed, preferred things this way, partly because it made diplomatic bargaining easier and partly because political power brokers have typically shown an almost visceral reluctance to operate in the open. But if any event dramatically exposed the incompetence of these elites and the dangers of their secret diplomacy, it was World War I. While the most 
visible (and audible) result of this exposure was the Wilsonian call for 'open covenants, openly arrived at', another message was received by Wright and Richardson.

As I interpret their prefatory remarks, each had begun to appreciate that another reason for secrecy was that the decision makers often did not 'know what they were doing'; that is, even after lengthy domestic debate over foreign or military policy, the elites made recurrently erroneous predictions as to the consequences of their actions. Further, these two scholars arrived at a judgment that was not only generous, but probably correct: that the problem lay not so much with the stupidity or ambition of the foreign policy elites, but more with their ignorance. In addition, they observed that this ignorance was not peculiar to the practitioners alone; the scholarly community was hardly better off.

Having arrived at these general conclusions, it was natural that they would then have some caustic observations on the absence of evidence, and the heavy reliance on 'brilliant, witty political discussion' (Richardson, 1960a, p. v.). This British meteorologist and pacifist also noted that 'many of those who are considered to be experts on foreign affairs do not base their opinions on historical facts, but on some sort of instinctive reasoning'. But, as the subsequent research of each makes clear, they saw the need for something more than historical facts, as gathered and interpreted by the standard diplomatic historian or political analyst. If the behavior of governments in the international setting was to become less destructive, the knowledge base from which they worked would have to be greatly improved. That is, if decision makers could more accurately predict - on the basis of historically observed regularities and theoretical inferences therefrom - the consequences of their decisions, there might be a decline in the frequency and magnitude of war. Even if that knowledge base served only to help challenge and question the assumptions behind our decisions, the error rate might be re- duced. Of course, while the acquisition and codification of such knowledge would be necessary, neither Wright nor Richardson thought that it would be sufficient; decision makers and attentive publics would also have to be able and willing to understand, cvaluate, and apply that knowledge.

\section{Typologies and taxonomies}

Given, then, the need for a more solid knowledge base in the emerging inter-disciplinary field of war/peace studies, where do we stand now? What kinds of knowledge have we acquired and how adequately has it been codified into theoretically coherent form? What are the dominant orientations, and what are the more promising of these? In order to address these questions, we need some sort of organizing framework, within which we can differentiate the several theoretical orientations as well as summarize our knowledge to date. The variety of frameworks is, of course, quite large, and people gravitate to one or another of them for all sorts of reasons, scientific or otherwise: nationality, social class, age, gender, education, personality, academic identity, foundation and governmental fashions, and even (!) on the basis of prior research findings.

\subsection{A familiar typology}

One of the more familiar ways of classifying - and often, selecting from among - the possible approaches, is to divide them into the standard categories of technological, economic, geographic, political, demographic, ideological, psychological, etc. As suggested, the advocates of any of these approaches often arrive at their position as a result of disciplinary affiliation, reflecting the oft-implicit premise that the academic discipline that one selects reflects one's 'belief' that its major explanatory variables will account for virtually all sorts of social outcomes. Choosing such a typology and one of its approaches may, however, reflect nothing more than the conviction that one studies best those phenomena that one knows best, and that such partial models and their 
findings must eventually be integrated into those generated within the other social sciences.

But regardless of the motives and assumptions, we usually end up with a typology that helps to perpetuate and legitimize these parochial orientations and to encourage the appearance, disappearance, and reappearance of those 'theories' that are all too typical of the no-growth, non-cumulative disciplines. Thus we find heavy, if not sole reliance on such factors as power discrepancies (Blainey, 1973), surplus capital (Lenin, 1939), business cycles (Secerov, 1919), demographic pressures (Organski, 1968), resource needs (Choucri \& North, 1975), elite personalities (Stoessinger, 1978), national moods (Klingberg, 1952; McClelland, 1961), misperceptions (White, 1968), and so forth. These at least have the virtue of resting upon variables that show some variation across time and place. But other alleged models of a single-variable sort fail to even recognize that a phenomenon as irregularly (and infrequently) distributed across time and space as war cannot be explained on the basis of relatively invariant phenomena. Thus, it is difficult to take seriously such putative explanations as the human drive for power (Morgenthau, 1948) or territory (Ardrey, 1966), the instinct of aggressiveness (Lorenz, 1967), or libidinous drive (Fornari, 1974).

In addition to the fact that most of the above orientations are rarely examined empirically, are seldom related to other explanations (Nelson \& Olin, 1979; Silberner, 1946), ignore the multi-dimensional complexities of the war-inducing process, show insufficient variation in their 'explanatory variables', and are overly responsive to current events, political pressures, and funding agency fads, they usually suffer from another fatal flaw. That is, they tend to overlook the critical distinction between international conflict and international war. While conflicts can arise out of an impressive range of social incompatibilities, the processes that lead to so frequent an event as conflicts are not necessarily those that lead to so infrequent an event as war. In a global system that is so poorly integrated in the structural or cultural sense, the relatively high frequency of serious international conflicts and military confrontations (about 225 involving the major powers alone since the Congress of Vienna) need not surprise us, whereas the relatively low frequency of war (fewer than 30 among those same powers in those 160 -odd years) surely calls forth our curiosity.

Then there is the distinction between necessary conditions and sufficient ones (Deutsch \& Senghaas, 1971). Many conditions are necessary for modern war: the fact that humans can behave aggressively and that many of them do seek power or territory under the proper stimuli; the availability of transport and weapons technology; centralized decision authority; some sort of credible justification, and so forth. While these may well be certain necessary conditions, it is far from clear that any single factor is sufficient to carry a conflict across the threshold to war.

We need, therefore, a typology that: a) recognizes the qualitative differences among competition, rivalry, and dispute on the one hand, and sustained military combat on the other, and that b) also recognizes the complex interplay of necessary and/or sufficient conditions reflecting a wide range of material, structural, cultural, and behavioral phenomena. In addition, it should aid in integrating what we have discovered with what we hope to discover, and if possible, illuminate the research path that links the two. A discrete check list will not suffice; an integrated, but multitheoretical, framework would seem to be essential. Let us turn, then, to a scheme derived from the general systems literature that might possibly help us to organize what we know, and think we know, and to help stimulate the most appropriate next steps. This scheme has been laid out in considerable detail elsewhere, along with an elaborate epistemological rationale (Singer, 1971), but its bare outlines can be summarized here. 


\subsection{A general systems taxonomy}

Since war is waged, contemplated, and conducted by and on behalf of human beings organized into a variety of social entities, and is not conducted by relationships or roles or system properties, it makes perfect sense to build our taxonomy around those entities, however transitory and/or amorphous they may turn out to be. All sorts of social groups can and do engage in sustained military combat, but since our concern here is with international war, we can confine ourselves to the most relevant sub-national, national, and extra-national groups, ranging at the sub-national level from the family and primary work group up through all sorts of secondary associations to political parties, government agencies, legislatures, cabinets, and armies.

When many such groups - at various levels of aggregation, and covering various functional sectors - are relatively unified and coordinated within a national territory, the resulting coalition may be called a national (or multi-national) state. The state or nation is the dominant unit of the international system, but for centuries before the emergence of that system, man was organized in many other types of social organization; and as other more effective groupings develop and attract the loyalty of their members, that pattern may be renewed, and it will be increasingly appropriate to refer to the global, rather than the international system. In any event, the nation is the major participant in international war, even though the probability of any such war, and its outcome, may well be influenced as much by the various sub-national and extra-national groupings with which the nation shares the world stage. There is an almost limitless range of levels of social aggregation at which the causes of war question might be addressed, but for the purposes of the discussion at hand, we will address only four of them: the international system (defined globally, regionally, or functionally, depending on the work being summarized); the inter-nation dyad; the single nation; and the decision making agency level. Social entities at any of these levels may be thought of as systems, embracing the attributes by which they are described, as well as the behaviors and interactions of the subsystems which make up the larger system; hence we distinguish here between the ecological and behavioral variables by which we seek to understand dynamic social phenomena.

Social entities from the individual up to the global system may be described in terms of three sets of attributes; ranged in order of tangibility and ease of operational measurement, they are material, structural, and cultural. Material attributes may be divided into three subsets, of minimal relevance to the individual human, but highly germane to any other entity: geographic, demographic, and technological. And by the structural attributes of a social system we mean the institutional and organizational phenomena by which economists, sociologists, and political scientists usually describe it. Structural properties may be of a relatively formal nature, embracing the types and powers of institutions that deal with legislative, administrative, judicial, banking, commercial, welfare, informational, and similar activities in the entity or system. But they also embrace such informal attributes as access to and influence over decision-making processes; the number and configuration of political parties and interest groups; the number and distribution of religious, linguistic, and ethnic aggregations; the social and geographical mobility of the population; the extent and configurations of pluralistic cross-cutting bonds; and the nature and stability of the resulting coalitions.

By the cultural attributes of a social entity, we mean strictly the distribution of the psychological properties of the individuals who comprise that particular system; this reductionist definition explicitly excludes any socalled emergent or organic properties of the system 'as a whole', so as to avoid reification and any suggestion that social groups may have personalities, purposes, etc. The cultural dimension embraces the distribution of 
individual personalitiy types, attitudes, and opinions, and extends to the way in which all three of these psychological attributes relate to the way things are, should be, and will be; these can be thought of, respectively, as perceptions, preferences, and predictions. We can, in turn, treat the distribution of personalities as national (or any other system's) character, that of attitudes as ideology, and that of opinion as cultural climate.

To summarize, the above set of dimensions should permit us to describe a nation or any social entity, compare it to itself at different points in time, and compare it to other entities at the same or different levels of analysis at the same or different point in time. To put it in Allport's suggestive language, these attributes permit us to deal with our objects of analysis in terms of their being and in terms of their becoming, and having done this, we can then move on to deal with their behaving and interacting.

While the distinction between behavior and inter-action (between/among actors) is selfevident, one of the inadequacies of the English language and the concepts conveyed by its vocabulary is that the word relationship carries so wide a variety of meanings, but it is used here in only two of its senses: that of comparison and that of connectedness. Thus, when we say that the political integration of system $X$ is very high in relation to that of system $\mathrm{Y}$, we are comparing the two systems on a particular set of attributes. The confusion, as well as the distinctions, between these two meanings is well illustrated by the notion of 'social distance'. Two systems may be close or distant in terms of their position on a given attribute scale, such as size, ethnic homogeneity, or structural complexity. They may also be close or distant in terms of their interdependence or their friendship, and there is absolutely no reason to expect that entities that are close in the sense of similarity will always be close in the sense of connectedness or interdependence as well, despite the frequency of this assumption (implicit or otherwise) in the social sciences.
Let me mention here two other sources of confusion. One is the relationship (sic) between relationships (in the sense of connections) among entities at one level of analysis and the structure of any system at the next higher level of aggregation; the other is the relationship between such relationships and interaction. To consider the first, many structural properties of a given system are inferred from observation of the relationships among its sub-systems. We are often told that a social system is more than the sum of its parts, but this bromide often leads us into all sorts of metaphysical pursuits, as we search for the emergent or organic properties of the system itself. I maintain that a system is nothing more than the sum of its parts, along with the relationships and interactions among them. This formulation is important not only because it helps eliminate much of the mysticism surrounding social entities, but because it quickly converts a difficult and costly process of observation and measurement into a relatively straightforward one: many structural attributes of a system may be inferred quite simply by observing the relationships among its component parts. And we can discover the cultural attributes of a system by observing the interactions among its components, but this requires a longer inferential leap, inasmuch as we must first be confident of the extent to which the behaviors comprising interaction actually reflect cultural perceptions, predictions, and preferences.

As to the other relationship - that between relationship and interaction - we note that the first may be thought of as a condition: the bonds and links that connect two or more social entities. While relationships are largely the consequence of interaction, and while we can often predict interaction events from observed relationships, the differentiation between relationship and interaction is critical to the empirical examination of many of our models and hypotheses. 


\subsection{Measuring the incidence of international war}

Before utilizing this scheme to examine the evidence as to which factors might cause, explain, lead to, make for, or account for fluctuations in the incidence of war, a brief digression is in order. Surprising as it may seem, scholars have been speculating on the causes of war for centuries before they tried to ascertain its empirical distribution, and even today many of our theoretical disagreements stem partly from the failure to identify our population of cases, and from differing conceptions and definitions of our outcome variable (Blechman \& Kaplan, 1978; Bloomfield \& Leiss, 1969; Bouthoul, 1951; Kende, 1971; Urlanis, 1960). But following on the work of Sorokin, Richardson, and Wright, the Correlates of War project at Michigan has assembled what seems to be the population of international (inter-state, imperial, and colonial) and civil wars involving one or more sovereign states any place in the world since the Congress of Vienna, and has presented the coding rules, resulting data, and summary statistics (Singer \& Small, 1972; Small et al., forthcoming).

In that handbook (Wages of War), we differentiate among four basic indicators of the incidence of war. The first is that of frequency, and is measured by the onset of sustained military hostilities between authorized armed forces of two or more sovereign national states culminating in at least 1,000 battle deaths. The second is severity, and is measured by the number of battle deaths resulting from a qualifying war; the third is magnitude measured in terms of nationmonths of war; and the fourth is that of intensity, measured in battle deaths per nation month or per capita. While frequency is measured only in the context of a given time and space domain, the other three indicators of the incidence of war can be applied to a given war as well as to all of the qualifying wars that occur in a specified time and space domain. In most, but not all of the studies summarized here, the Correlates of War data base and indicators have been used, and unless the choice of indicator makes an appreciable difference, the results will be reported in terms of the simplest indicator of war: its frequency.

Yet another consideration when seeking to account for the fluctuations in a given phenomenon is the extent to which they show a discernible regularity across time or space. While I would not accept the proposition that goodness of fit between a given distribution and one or another statistical model permits a legitimate inference as to the processes that produced that distribution, such regularities can certainly be suggestive (Horvath, 1968; Voevodsky, 1969; Weiss, 1963). Perhaps the most suggestive fit would be that of periodicity, on the assumption that a strong cyclical pattern might imply a degree of inexorability in international warfare. And, given the frequency with which cyclical patterns have been asserted, as well as the variety of inferences drawn from these putative patterns (Alcock, 1972; Davis et al., 1978; Denton \& Phillips, 1968; Dewey, 1964), it may be worth reporting the results of a fairly systematic search for them. Simply put, we have found only the weakest trace of periodicity in the incidence of all international warfare over these 160 years, with a barely discernible cycle of 20-odd years (Singer \& Small, 1972). More important, when we look at the war experiences of the more war-prone nations one at a time, virtually every conceivable technique fails to produce evidence for any kind of regularity (Singer \& Cusack, 1980). Thus, it is perfectly true that there are peaks and troughs in the time plots of war at both the national and the systematic levels, but the time intervals between those peaks and/or troughs are of sufficiently random length to support the sceptical conclusions of Sorokin (1937, p. 359) and Richardson (1960a, pp. 129-30 and 140). I would not, however, want to foreciose further research into the question, especially from the war expansion and contagion perspective. That is, despite the diverse results - stemming from diverse domains, indicators, and techniques - the 
evidence for addiction to war on the part of the system or any nation seems weak. But a close reading of Davis, Duncan, and Siverson (1978) and Siverson and King (1980) suggests that more complex models of diffusion and contagion - via alliance bonds might well stand against the empirical test.

If war itself does not appear and re-appear in a regular cyclical fashion, it is unlikely that it results to any important extent from any other single-factor cycle, be it commercial, agricultural, climatic, or demographic. Rather, if there are indeed cyclical phenomena at work, there must be several of them involved in this process (Hart, 1946; Sorokin, 1937), with their concatenations falling at relatively irregular intervals. While there seems to be no concentrated research effort in this direction at the moment, it certainly appears to be worth pursuing further, perhaps when more is known regarding the time-space distributions of some of the more promising explanatory variables. Let us, then, attempt a brief and admittedly selective survey of these latter as they impinge on the incidence of international war.

\section{Findings to date on the incidence of war} To reiterate a point that has already been noted, there is no substitute for a good theoretical model when laying out an empirical investigation, but when we are not nearly far enough along to even specify the key variables of such a model, we have little choice but to work within a multi-theoretical framework and get on with our more inductive efforts. The problem now is one of identifying the results of the inductive work to date, some (but not all) of which has been shaped by the proposed framework, and to see how far it permits us to summarize and synthesize these diverse findings. We will work with three of the levels of aggregation noted earlier, and within each, look at the extent to which the several classes of variables seem to be accounting historically for the incidence of war. And, reflecting my strong suspicion that variables of a systemic and dyadic sort will turn out to be more powerful than those at the national and the decision-making levels of aggregation, let me deal with the findings at these levels in that order.

While it is often a rule of thumb to look first at the phenomena that are closest - in space or time - to the outcome we seek to explain, there seem to be reasonable grounds for not doing so in the case of war. While these grounds are far from conventional and the evidence for them is sparse, space limitations permit only stark assertions here; for a more detailed justification, see Singer (1961 and 1976). First, I assume that there is a great deal of homogeneity in the intellectual style of foreign policy/national security decision makers from nation to nation and from decade to decade over the past century or so. Similarly, there seems to be a remarkable homogeneity in the decision rules that nations follow, especially when they are in conflict, again irrespective of such allegedly critical distinctions as regime type, national culture and ideology, and level of economic development (Rosenau, 1966). These two assumptions suggest that we will not find a great deal of variation at the decisional and national levels, and therefore should not expect the attributes of nations or their decision makers to be very powerful in explaining so varying an outcome as war/no war.

A second consideration that follows quite logically is that most of the variation in the behavior of nations in conflict will be accounted for, not by their internal attributes, but by variation in their environment. That environment can, in turn, be viewed as having two basic components; the dyadic relationship with another nation, and the regional or global systemic context in which the conflicting nation finds itself. From this, it follows that we might expect to find the dyadic relationship and the properties of the system to carry us further in accounting for the incidence of international war than would the attributes of the nations or their decision making organizations (Zinnes, 1980a). Thus, we will begin with the systemic environment and examine some of the empirical evidence to date, and then move on to the effects of 
dyadic phenomena. But, to reiterate, the selection is intended to be more representative and suggestive than exhaustive.

\subsection{Systemic attributes}

Despite the possible attractiveness of the above argument, few other investigators into the war/peace question have accepted it, and as a result, a fair fraction of research on the systemic conditions associated with war has emanated so far largely from the Michigan Correlates of War project. Further, of the three types of systemic conditions - material, structural, and cultural - most of the reproducible evidence to date reflects the structural dimension (Sullivan, 1976). Unfortunately, there is little systematic work on such material attributes of the system as weapons technology, industrial development, resource limits, climate, or demographic patterns. Similarly, outside of some preliminary efforts by Kegley et al. (1979), Choi (1978), and Gantzel (1972) little effort has been invested in the search for systematic connections between cultural conditions and the incidence of war. On the other hand, researchers of a scientific bent have been as assiduous in their examination of structural correlates of war as their methodologically traditional colleagues, and it is to that literature that we now turn.

Perhaps the most plausible of the system's structural attributes in the war/peace context is that of the configurations generated by alliance bonds, with those generated by distributions of power following closely behind. Looking first at the structural characteristic known as bipolarity, we usually have in mind the extent to which the nations in a given geographical region, or in the major power sub-set (a functional 'region'), or world-wide, are clustered into two clearly opposed coalitions. While there are several definitions of bipolarity and rather diverse operational indicators, it generally implies the degree of conformity to an 'ideal' condition in which all of the nations are - via military alliance - in one or another of two equally powerful coalitions with no alliance bonds between the polar blocs, and full bondedness within each. While such a set of conditions has never obtained, the reasoning is that even an approximation would so severely hamper the conflict resolving efficacy of the pluralistic cross-cutting, multiple balancing mechanism of the system as to make conflict escalation and war much more likely (Deutsch \& Singer, 1964; Waltz, 1964; Rosecrance et al., 1974; Kaplan, 1954; Liska, 1956). But like all too many theoretical hunches in the world politics field, there is an equally plausible counter-argument: that so clearly bipolar a system structure would eliminate all ambiguity as to who is on whose side, or as to the possibility of military victory, that war would just never be considered. Rather, according to this orientation, war occurs when there is ambiguity, either because behavior becomes less predictable and governments stumble into war, or because governments have a 'drive toward certainty', and war helps to clarify the picture.

In any event, the research findings to date only partially resolve the theoretical disagreements. In one of the first systematic analyses, Singer and Small (1968) found that the relationship between their indicators of polarity and war differed in the 19th and 20th centuries. In the earlier epoch, higher polarity levels tended to be followed by lower levels of international war, but in the period since 1900 , fluctuations in the incidence of war were positively associated with the fluctuations in polarity. In a follow-up, Wallace (1973) used a somewhat different indicator of polarity and found a curvilinear association, with war levels generally associated with very high bipolarity scores or very low ones, suggesting - for the entire 18161965 period - that there may be an optimal level of three or four relatively discernible alliance clusters, with war levels quite low when those intermediate conditions obtain. In a third and more recent analysis of the question, Bueno de Mesquita (1978) found that fluctuations in war were accounted for less by the level of bipolarity in the system than by the direction and rate of change in 
the alliance configurations that might produce such bipolarity. That is, the amount of war in the system since the Congress of Vienna tended to rise when the 'tightness' of alliance clusters was on the increase. Even more confusing are Levy's finding (1979) that bipolarity makes for maximum stability and unipolarity for maximum war, and Wayman's finding (1981) that cluster polarity exercises a different effect than power polarity. Perhaps Ostrom and Aldrich (1978, p. 765) summarize things best in reporting that 'our results have a distinctly negative flavor'.

As might be expected, there are several interesting extensions of the bipolarity-war hypothesis. The simplest is that since alliances involving one set of major powers will generally be in opposition to other majors, the greater the percentage of major powers in alliance, the greater the bipolarity of the system as a whole, and thus the greater (or lesser) will be the incidence of war in the ensuing years. Once again, the empirical findings are mixed; Singer and Small (1968) found that their alliance aggregation indicator, which was indeed highly correlated with their bipolarity index, predicted positively to the incidence of war in the 1900-1945 period, but negatively in the $1816-1899$ period. Imposing more stringent analytical tests and slightly different indicators, Ostrom and Hoole (1978) turned up similar, but considerably weaker patterns.

A more complex version of this systemic hypothesis can be interpreted in two ways. One is that the concentration of military and industrial capabilities tends to follow the concentration of national coalitions and groupings (especially the majors), and that the concentration of these capabilities should have the same effect on the incidence of war as the concentration of the nations into a small number of tight polar groupings. While this isomorphism does occur from time to time, it is not constant enough to make this interpretation very compelling. Thus, one takes a more generalized view and treats both types of concentration as producing a high degree of clarity in the system's struc- ture. And to the extent that the systemic environment is clear and unambiguous as to: a) who will fight on which side if a conflict escalates to war, and b) which side will probably win that war, the decision makers are thought to be less likely to either entertain the war option or to merely stumble into war.

Regardless of the theoretical interpretation, the empirical investigations lead once more to inconsistent results. And, as before, a major anomoly is the inter-century one. In the 19th century, high concentration of capabilities in the hands of a very few powers makes for increases in the incidence of war, while more equal distributions are associated with low levels of war (Singer, Bremer and Stuckey, 1972). But in the period 1900-1965, high concentrations lead to low levels of warfare and low concentrations are associated with higher levels of war. In a follow-up study, Champion and Stoll (1980) went a step further and: a) introduced an important control variable, classifying each major power as either 'satisfied' or 'dissatisfied' on the eve of each war as reflected in the historians' consensus; and b) calculated the concentrations in terms of coalitions, rather than concentrations in terms of the nations separately and individually. These modifications appreciably enhanced the post-dictive power of the capability distribution model across the full time period, suggesting that if the blocs have indeed been accurately identified and the powers accurately classified on the 'satisfaction' dimension, this systemic factor may be of considerable importance. But as the authors remind us, the validity of these additional indicators remains to be more fully demonstrated. In an interesting variation on this theme, Cannizzo (1978) examined the effect of such capability configurations on the major powers individually, and found that these were far from uniform; concentrations and changes therein strongly affected France, Italy, and Austria-Hungary, for example, while having little impact on the war experiences of England, Japan, and Russia. Wayman (1980) found that wars oc- 
curring under conditions of high concentration are less severe than those occurring when capabilities are more evenly distributed.

Another factor - related to the others in the sense that it taps the structural clarity dimension - is that of status inconsistency, aggregated to the systemic level. In two of the earlier investigations, Wallace (1971) and East (1972) found moderately clear associations between the incidence of international war and the extent to which the rank scores of the nations on the material capability and diplomatic importance dimensions were inconsistent with one another. That is, the more similar the systemic pecking orders on power and on prestige, the less war-prone the system was in the years following. On the other hand, the inquiries by Ray (1974) and Gochman (1980) produced more ambiguous results, perhaps due in part to the use of different indicators.

\subsection{Dyadic conditions}

While there is a clear conceptual difference between the structural characteristics of a system and the relationships among the component units of the system, it is worth reiterating their empirical and conceptual connections. As noted earlier, most systemic properties rest upon, and can be inferred from, the links and bonds among the components, and while some scholars have sought their indicators of system structure in the triad (Harary, 1961), most of the databased work has been restricted to the more manageable 'two-body problem', to borrow from the vocabulary of physics. Following the distinction noted earlier, we will treat dyadic conditions of a relational sort first, and then turn to those of a comparative sort, resting not on the links, but on the similarities, between nations.

As to the former, we again find the familiar emphasis upon alliance bonds, followed by the bonds created via membership in discernible diplomatic clusters, trading blocs, and international organizations. First, we discover that, in general, nations with formal and long-standing alliance bonds experience a significantly higher frequency of war than do those without them (Small \& Singer, 1966); on the other hand, Sabrosky (1980) found that nations that were allied to one another had a very low probability of going to war against one another. Neither case suggests anything as to the intentions of the alliance makers (Singer \& Bueno de Mesquita, 1973). Looking at another type of bond, Skjelsbaek (1971) found that war opponents tended to decrease their shared intergovernmental organization memberships in the five-year period preceding the onset of war, and Singer and Wallace (1970) found that while most IGOs were founded after the termination of war, there was virtually no relationship between the number of them in the system and the amount of interstate war experienced in the subsequent five years. More surprisingly, Gochman (1980) found that militarized disputes between major trading partners were more likely to escalate to war than were disputes between states that did not heavily trade with each other.

Shifting from the role of dyadic bonds and associations in accounting for the incidence of war to that of similarities and differences, the ubiquitous dimension of power again captures most of our attention. The theoretical argument is rather direct: even though sub-military conflict seems to be no more likely between nations of very unequal strength than between those of approximate parity, this factor should become more critical as the war threshold is approached. The familiar dictum is that the weaker dare not fight and the stronger need not; the corollary is that one purpose of war is to ascertain which party is stronger when any doubt does exist.

While the evidence on this question is relatively consistent, the final word has hardly been said. For example, Garnham (1976a) found that equality in population reduced the likelihood of dyadic war, but that equality in geographical size or industrial base did not, in the $1816-1965$ period. Controlling for geographical contiguity, however, both he (1976b) and Weede (1976), as 
well as Barringer (1972) and Wright (1965), found that nations that were approximately equal in material capabilities were significantly more likely to carry their disputes to war than were nations of discernible disparity. Further, Stoll and Champion (1977) found that serious disputes were more likely to escalate to war if the weak side was the initiator of the dispute; disputes initiated by the stronger side were less likely to end in war. Mihalka (1976) found that once military force was threatened or used, the greater the disparity in capabilities of the disputants, the less likely the dispute was to escalate to hostilities. More recently, Singer and his colleagues (1979a) found that while only $13 \%$ of all major power militarized disputes since 1816 escalated to war, that figure rose to $20 \%$ when the parties were approximately equal in military terms, and to $75 \%$ if such parity was combined with rapid military buildup during the three years prior to the dispute.

A second emphasis in this literature is more diffuse, but worth noting briefly, given the theoretical pervasiveness of its assumptions. That is, the more similar two nations are in terms of certain political or cultural attributes, the more friendly their relationship might be expected to be, and the more friendly they are, the less frequently or severely might they be expected to wage war against one another. Here, too, Richardson (1960a) was the first to look into the question systematically, and he found little historical evidence to support the classical view. For the period 1820-1949 and using his population of 300 -odd wars and military disputes, he found that neither a common language nor a common religion had a depressing effect on the incidence of dyadic war (pp. 230-31). To the contrary, as he himself demonstrated (pp. 285-86) and as others have confirmed (Gleditsch and Singer, 1975), geographical contiguity is the confounding variable. That is, since geographical neigbors are not only more likely to be culturally similar but also to have more sources of conflict and to be more accessible to one another's armies, it follows that such similarities should actually be related to dyadic war in the positive direction (Gantzel, 1972).

These findings lead, in turn, to another of the more interesting paradoxes in research to date. Reference is to the effect of common boundaries, with the reasonable hypothesis that the greater the number of immediate neighbors a nation has, the more frequently it will be drawn into warfare against one or another of them. While Richardson's data (1960a, p. 177) tend to support this hypothesis, the findings of Starr and Most (1978) do not. Rather, they find an inverse relationship between a nation's war proneness and the number of immediate neighbors. Nor should these results be surprising, when we consider that the number of direct neighbors is physically a function of a land-locked nation's geographic size vis-à-vis that of its neighbors. The longer its boundaries, the greater the number of others that can border on it, and the smaller these latter are, the more numerous they can be. From this, it follows that the greater will be the discrepancy between its size (and strength, all else being equal) and theirs, and given the finding that war is more likely between equals, it again follows that the frequency of war should be lower.

\subsection{National attributes and relationships}

In an earlier section $I$ indicated that national attributes seemed less crucial in accounting for war than either systemic or dyadic conditions, and before summarizing the evidence to date, let me expand on that assertion.

Briefly put, the exigencies of survival in an international system of such inadequate organization and with so pervasively dysfunctional a culture require relatively uniform response. That is, for a national entity to adapt to and survive in such an environment, it must achieve a fair degree of political mobilization, military preparedness, and political centralization. Despite great differences in tradition and culture, or great ap- 
parent differences in political regime and economic arrangements, these external considerations tend to reinforce the essential domestic similarity of national states, regardless of their size, strength, level of economic development, etc.

To what extent does the empirical evidence to date support this alleged lack of crossnational variation in the attributes that might be associated with the incidence of war? On the one hand, certain of these attributes do seem to be related to the frequency and/or severity of national war experiences(Richardson, 1960a; Rummel, 1972), with overall military-industrial capabilities the most potent predictor. In a systematic examination of the relationship between a six-dimensional index of such capabilities and war proneness since the Congress of Vienna, Bremer (1980) found a very strong positive correlation between the strength of nations (including industrial development and military preparedness) and their tendency to go to war. Using a more restricted indicator, reflecting the size of the military establishment, and using more general indicators of foreign conflict, several studies further confirm this positive association with national strength (Naroll, 1969; Choucri and North, 1975; Small, 1978; Weede, 1970).

On the other hand, if we turn to more complex models that might link national characteristics to war proneness, the findings are considerably more ambiguous. Applying the sociological concept of status inconsistency to nations whose material capabilities are high and whose attributed diplomatic status scores are low (or vice-versa), neither Ray (1974) nor Gochman (1980) found any consistent pattern. Another domestic characteristic that has often been thought of as contributing to national war proneness is that of domestic instability. Yet no investigation identified much of an association until Wilkenfeld (1973) controlled for regime type, and found, for part of the post-World War II period, several clear associations. However, looking at regime type alone and examining the full $1816-1965$ period, Small and Singer (1974) found that autocratic and democratic regimes were equally likely to both initiate wars and to become embroiled in them, but Haas (1965) found, at least for the twentieth century, that democratic regimes were less war prone than authoritarian ones. He also concludes in the same study that wealthy urbanized nations, especially during periods of social strain, are particularly susceptible to war involvement.

Shifting from attributes of an essentially internal sort to external relationships, the dimension most often examined is that of alliance bonds. In studies covering members of the interstate system since 1816 , both Singer and Small (1966) and Siverson and King (1978) find a strong positive association between alliance involvement and war proneness; this is not to suggest that the relationship rests on the high reliability of alliance commitments (Sabrosky, 1980). And, given the well-known association between high capabilities and high alliance involvement, as well as that between capabilities and war proneness, this should come as no surprise. On a related dimension and picking up the geographical variables summarized earlier in the dyadic context, Richardson (1960a) found a positive relationship between the number of neighbors a nation had and the frequency of its wars from 1820 to 1945 , and Wesley (1969), Weede (1970), Midlarsky (1975), and Starr and Most (1978) found relatively similar patterns for comparable spatial-temporal domains. Finally, Gleditsch and Singer (1975) examined the effect of a nation's mean distance from all other sovereign members of the system, and they, too, found a positive relationship; the more centrally located they were, the more war they experienced.

The tentative inference from this limited set of studies is that such basic geo-strategic factors as location and strength seem to be of importance, but that despite persuasive arguments to the contrary (Rosenau, 1966), domestic factors of a less material sort would appear to be rather negligible in accounting for the war proneness of individual nations. 


\subsection{Behavioral and interactional patterns}

To this juncture, our focus has been on the extent to which the frequency and magnitude of war might be accounted for historically by the contextual and ecological variables: fluctuations in systemic, dyadic, or national conditions. Following the check list implied in the taxonomy, this leaves untouched the question of behavior itself: to what extent can we account for war by the actions and interactions of the nations? Given the emphasis on diplomatic and military behavior in the speculative literature on war, one might expect to find a respectable body of empirical work on the question. The fact that we do not, however, need not be very surprising. First of all, behavioral phenomena are more elusive and seem to be more difficult to observe and measure. Second, a good many researchers suspect that behavioral patterns are so heavily determined by the ecological conditions summarized above that these former will account for very little variation in our outcome. Third, and closely related, is the suspicion that we can treat ecological variables as surrogates of behavior, given their assumed covariation, and thus avoid all of the grief associated with the observation and measurement of behavior.

Be that as it may, there is a modest body of empirical work in which behavior patterns serve as predictors, and once again Richardson offers a convenient point of departure. Perhaps his most important contribution is found in the posthumous Arms and Insecurity (1960b), where he derives and then puts to the test a simple differential equation designed to capture the essence of an interactive arms race. Vis-à-vis the arms expenditure patterns preceding the two World Wars, the model offers a fairly good fit, and generally supports the notion that each protagonist's annual increase will be a function of the other's absolute expenditure in the previous year, controlling for a fatigue factor and an exacerbation factor.

These analyses have stimulated the development of a rich and diverse array of follow-up models, a fair number of which have been tested against various 19th and 20th century arms interaction processes. While it would require a major review article to summarize and interpret this body of research (Kurakawa, 1978; Luterbacher, 1974; Zinnes, 1980b) two general conclusions seem justified. One is that we have not yet been able to separate the effects of the domestic and foreign stimuli at the various stages of arms races, and the other is that we have yet to differentiate between the profiles or 'signatures' of those that have ended in war and those that have not (Singer, 1970). But two important findings have resulted from Wallace's work in this area. In an earlier study (1971), he not only found that status inconsistency levels in the international system predicted system-wide increases in military expenditures, but also that these increases predicted in turn the incidence of war. In a later analysis (1979) Wallace found that if two nations started a military confrontation, their likelihood of crossing the war threshold was considerably lower if they were not in an arms race with one another, but much higher if they were.

An even more elusive problem arises when we shift from military expenditures and arms acquisition to less easily observed behavior such as the diplomatic moves and countermoves associated with the escalation of conflict. But a satisfactory coding and scaling scheme has been developed (Leng and Singer, 1977). In some preliminary analyses, Leng (1980) found that the use of threats had a higher probability of ending in war when met with a defiant counter-threat, whereas there is no clear association between the mere frequency of threats and the onset of war. In an earlier set of investigations, North et al. (1964) combined behavior and perception in order to examine their reciprocal effects in a number of crises, particularly that preceding World War I. In general, they found a propensity toward over-estimation of the adversary's intentions (compared with his actual behavior) and an under-estimation of his relative capabilities, the combination of which leads to escalatory behavior. 
Not surprisingly, and despite the attention of diplomatic historians and traditional political scientists, the systematic examination of the relationship between behavioral phenomena and war has lagged discernibly behind that of the other three sets of factors discussed earlier. While the explanation lies partially in the observation and measurement problem noted above, this lag also reflects the reasonable idea that the more we first discover regarding the effects of the ecological conditions, the greater the theoretical mileage we will obtain from subsequent analyses of the behavioral and interactional phenomena.

\section{Conclusion}

While this summary hardly suggests that we are well on the way to understanding the causes of war and conditions of peace (to use Wright's phrase), some modest optimism would not be completely out of place. That is, despite the limited amount of research and the relative lack of convergence in our findings, there are two grounds for believing that we are no longer moving in non-cumulative circles. First, we are finally seeing systematic research that rests on reproducible evidence, and after several centuries of preoperational speculation, this is to be applauded. Second, despite the diversity of theoretical orientations, there seems to be a growing awareness that the resulting paradigms and investigations need not be incompatible.

On the one hand, my sense is that researchers in the war-peace sector are increasingly aware of the difference between explaining the high incidence of recurrent conflict and rivalry of a non-military sort, and explaining the low - but destructive incidence of war. The range of models intended to address the former question is, admittedly, impressive in its diversity. But that, in my judgment, is a less critical problem; conflict is ubiquitous in all social systems and the problem is not to prevent it, but to reduce the frequency with which it becomes socially destructive. Thus, when we shift from conflict in general to war in particular, we find a diminished and more manageable array of theoretical models (Burton, 1962; Hoffmann, 1965; Holsti, 1972; Kaplan, 1957; Wallensteen, 1973; Midlarsky, 1975; Russett, 1974). And, on the other hand, a close scrutiny of these models shows a remarkable overlap, if not convergence. To illustrate, let me mention some of the emphases found in the literature most frequently: realpolitik, arms race, power transition, economic development, and imperialism. There are indeed those who insist that such models are not only inconsistent with one another logically and empirically, but also not even subject to comparative analysis and testing. There are even those who insist on a different epistemology and assert that the western scientific method is inappropriate to the examination of rival models and hypotheses. But my suspicion is that their numbers and influence are on the wane, and that a compelling theoretical convergence could encourage a more open-minded examination of the empirical evidence.

In order to move toward such a theoretical convergence, two prior steps would seem necessary. First, we need to identify the extent to which these competing models rest upon similar explanatory variables. Given the Babel-like discourse of theorizers and practitioners, this might appear to be impossible. But as systematic empirical work goes forward, one inexorable consequence is the translation of ideologically loaded verbalization into operationally defined variables, and the evidence to date is that devotees of rather diverse approaches can agree on (at least) the face validity of these indicators. Moreover, it looks as if a rather wide range of putatively explanatory concepts can be validly translated into identical indicators. Thus, 'defining our terms' and operationalizing our variables may well reveal a considerable degree of convergence amongst theoretical models that have often been thought of as hopelessly divergent and incomparable.

Second, we need to recognize that at rock bottom the most important difference 
amongst the contending causes of war models is that of the foreign policy decision process. That is, each model assumes - often implicitly - a different class of decision makers in power, and each postulates a different set of decision rules. Thus, one strategy might be to conceive of the policy making process in terms of interest aggregation, with the decision makers seen as trying to respond to and balance a complex array of international incentives and constraints visà-vis an equally complex array of domestic interests, including their own. Once those assumptions and postulations have been teased out of the verbal models, our highly general paradigm might then be converted into operational versions of the several more specific models. Note that we have assumed, to this juncture, a high degree of homogeneity in decision makers and the rules they employ, but to move closer to a full explanation, that assumption would have to be relaxed.

These assumptions, however, should be put to the empirical/historical test directly, and this is why the research described in the body of this paper can be so valuable. It is one thing to observe and then classify the backgrounds and interest group affiliations of foreign policy elites in a wide range of nations across an appreciable span of time; while this research task is far from complete, it is clearly manageable. But the decision rules that they employ, and the utilities that they assign to various outcomes in the economic, diplomatic, and military sectors will remain forever beyond the range of direct observation. Thus, we have little choice but to rely on careful inference, and the most solid basis for inferring their decision criteria will be found in the sort of evidence discussed above, especially when embedded in computerized representations of the historical process (Alker and Brunner, 1969; Bremer, 1977). Under which systemic, dyadic, and national conditions do which foreign policy elites respond to which behavioral stimuli of which other nations in which specific fashion? The more fully we can answer these empirical questions, the more reliably can we infer the decision rules that are at work. And the more we can check these inferences against those that are embedded in the rival models, the closer we can get to their confirmation and disconfirmation.

This brief overview leaves out a great deal of important detail, just as our survey of the evidence to date is far from complete; a more complete picture emerges in three recent volumes from the Michigan project: Explaining War, 1979; Correlates of War I: Research Origins and Rationale, 1979; and Correlates of War II: Testing Some Realpolitik Models, 1980. But these pages should serve to remind us that the causes-of-war question is not only a researchable one, soluble in principle. They also serve to remind us that the task is finally under way, and if the scientific talent and the necessary support can be mobilized, we may yet be in time to put an end to one of the most destructive and dysfunctional activities known to human history.

\section{REFERENCES}

Alcock, N.Z. 1972. The War Disease. Oakville, Canada: Canadian Peace Research Institute.

Alker, H., and Brunner, R. 1969. Simulating international conflict. International Studies Quarterly, 13/1: $70-110$.

Ardrey, R. 1966 The Territorial Imperative. New York: Atheneum.

Barringer, R. E. 1972. War: Patterns of Conflict. Cambridge, Mass.: MIT Press.

Blainey, G. 1973. The Causes of War. New York: Free Press.

Blechman, B. M. and Kaplan, S. S. 1978. Force Without War. Washington, D. C.: Brookings Institute.

Bloch, I. 1899. The Future of War. New York: Doubleday \& McClure.

Bloomfield, L. and Leiss, A. 1969. Controlling Small Wars. New York: Knopf.

Bouthoul, G. 1951. Les Guerres: Elements de Polemologie. Paris: Payot.

Bremer, S. A., Singer, J. D. and Luterbacher, U. The population density and war proneness of European nations 1816-1965. Comparative Political Studies, 6/3: 329-348.

Bremer, S. A. 1977. Simulated Worlds. Princeton, N. J.: Princeton Univ. Press. 
Bremer, S. A. 1980. National capabilities and war proneness. In Correlates of War II: Testing Some Realpolitik Models, ed. J. D. Singer. New York: Free Press.

Bueno de Mesquita, B. June 1978. Systemic polarization and the occurrence and duration of war. Journal of Conflict Resolution, 22/2: 241-267.

Bueno de Mesquita, B. 1981. The War Trap. New Haven, Conn.: Yale Univ. Press.

Burton, J. W. 1962. Peace Theory. New York: Knopf.

Cannizzo, C. 1978. Capability distribution and major power war experience, 1816-1965. Orbis, 21/4: 947-957.

Champion, M. and Stoll, R. In press. Capability concentration, alliance bonding, and conflict among the major powers. In Alliances and International Conflict, ed. A. N. Sabrosky. Philadelphia: Foreign Policy Research Institute.

Choi, K. L. 1978. An Empirical Investigation of the Relationship Between International Legal Norms Relevant to the Control of Violence and the Amount of International War. Seoul, Korea: Department of Political Science and Diplomacy, mimeo.

Choucri, N. and North, R. C. 1975. Nations in Conflict. San Francisco: W. H. Freeman.

Davis, W., Duncan, G. and Siverson, R. 1978. The dynamics of warfare, 1816-1965. American Journal of Political Science, 22/4: 772-792.

Dedring, J. 1976. Recent Advances in Peace and Conflict Research. Beverly Hills: Sage.

Denton, F. H. and Phillips, W. 1968. Some patterns in the history of violence. Journal of Conflict Resolution, 12/2: 182-195.

Deutsch, K. W. and Singer, J. D. 1964. Multipolar power systems and international stability. World Politics, 16/3: 390-406.

Deutsch, K. W. and Senghaas, D. 1971. A framework for a theory of war and peace. In Search for World Order, ed. A. Lepawsky et al. New York: Appleton-Century. pp. 23-46.

Dewey, E. R. 1964. The 177-Year Cycle in War, 600 B. C. - A.D. 1957. Pittsburgh: Foundation for the Study of Cycles.

East, M. A. 1972. Status discrepancy and violence in the international system: An empirical analysis. In The Analysis of International Politics, ed. V. Davis et al. New York: Free Press. pp. 299. 319.

Ferris, W. H. 1973. The Power Capabilities of Nation States. Lexington, Mass.: Lexington Books.

Fornari, F. 1974. Psychoanalysis of War. Garden City, N. Y.: Doubleday.

Galtung, J. 1964. A structural theory of aggression. Journal of Peace Research, 1/2: 95-119.

Gantzel, K. J. 1972. System und Akteur: Beiträge zur Vergleichenden Kriegsursachenforschung. Düsseldorf: Bertelsmann.
Garnham, D. 1976a. Dyadic International War, 1816-1965: the role of power parity and geographical proximity. Western Political Quarterly, 29/2: 231-242.

Garnham, D. 1976 b. Power parity and lethal international violence 1969-1973. Journal of Conflict Resolution, 20/3: 379-394.

Garnham, D. 1979. The Causes of War: Systemic Findings. Milwaukee, Wisconsin: University of Wisconsin Department of Political Science.

Gleditsch, N. P. and Singer, J. D. 1975. Distance and international war 1816-1965. Proceedings of the International Peace Research Association, fifth general conference. Oslo, 481-506.

Gochman, C. S. 1980. Status, capabilities, and major power conflict. In Correlates of War II: Testing Some Realpolitik Models, ed. J.D.Singer, New York: Free Press.

Haas, M. 1965. Societal approaches to the study of war. Journal of Peace Research, 4: 307-323.

Harary, F. June 1961. A structural analysis of the situation in the Middle East in 1956. Journal of Conflict Resolution, 5/2: 167-78.

Hart, H. 1946. Depression, war, and logistic trends. American Journal of Sociology, 52: 112-122.

Hoffman, S. 1965. The State of War. New York: Praeger.

Holsti, O. 1972. Crisis, Escalation, War. Montreal: McGill-Queens Univ. Press.

Horvath, W. J. Jan. 1968. A statistical model for the duration of wars and strikes. Behavioral Science, 13/1: 18-28.

Kaplan, M. A. 1957. System and Process in International Politics. New York: John Wiley.

Kegley, C. W., et al. (eds.). 1975. International Events and the Comparative Analysis of Foreign Policy, Columbia, South Carolina: University of South Carolina Press.

Kegley, C. W., Raymond, G. A., Choi, K. L. August 1979. Fluctuations in Legal Norms and Arbital Behavior, 1825-1970: indicators of major power conflict? Columbia, South Carolina: Department of Political Science.

Kegley, C. W. 1979. Measuring transformations in the global legal system. In Law Making In The Global Community, ed. M. G. Onuf. Princeton: Princeton University Press.

Kende, I. 1971. Twenty-five years of local wars. Journal of Peace Research, 8: 5-22.

Klingberg, F. L. 1952. The historical alternation of moods in American foreign policy. World Politics, 4/2: 239-273.

Kurokawa, S. 1978. A simple model of arms races: Richardson's model revisited. Prepared for delivery at the Hiroshima, Japan Conference of the Peace Science Society (International).

Leng, R. J. 1980. Influence strategies and interstate conflict. In The Correlates of War II: Testing Some Realpolitik Models, ed. J. D. Singer. New York: Free Press. 
Leng, R. J. and Singer J. D. 1977. Towards a multitheoretical typology of international behavior. In Mathematical Approaches to International Relations, ed. Bunge, Galtung \& Malitza, Bucharest: Romanian Academy of Social \& Political Sciences, 71-93.

Lenin, V. I. 1939. Imperialism. New York: International Publishers.

Levy, J. S. 1979. The polarity of the system and international stability. International Studies Association. Mimeo.

Liska, G. 1956. International Equilibrium. Cambridge: Harvard University Press.

Lorenz, K. 1967. On Aggression. New York: Bantom Books.

Luterbacher, U. 1974. Dimensions Historiques de Modeles Dynamiques de Conflict. Leiden: A. W. Sijthoff.

McClelland, D. 1961. The Achieving Society. New York: Free Press.

Midlarsky, M. I. 1975. On War. New York: Free Press.

Mihalka, M. 1976. Interstate Conflict in the European State System, 1816-1970. Unpublished Doctoral Dissertation. Ann Arbor, Mich.: University of Michigan.

Morgenthau, H. J. 1948. Politics Among Nations. New York: Alfred A. Knopf.

Naroll, R. 1974. Military Deterrence in History. Albany: State University of New York Press.

Nelson, K. L., Olin, S. C. 1979. Why War?: Ideology, Theory and History. Berkeley, Calif.: Univ. of California Press.

North, R. C., Brody, R. A., Holsti, O. R. 1964. Some empirical data on the conflict spiral. Peace Research Society Papers, 1: 1-14.

Ostrom, C., Aldrich, J.H. Nov. 1978. The relationship between size and stability in the major power internationa! sysiem. American Journal of Political Science, 22; 743-771.

Ostrom, C. and Hoole, F. June 1978. Alliances and war revisited: a research sote. International Studies Quarterly, 22: 215-235.

Organski, A. F. K. 1968. World Politics. New York: Alfred Knopf.

Ray, J. L. 1974. Status inconsistency and war involvement in Europe, 1816-1970. Peace Science Society Papers, 23: 69-80.

Ray, J. L. 1980. The measurement of system structure. In The Correlates of War II: Testing Some Realpolitik Models, ed. J.D. Singer. New York: Free Press.

Richardson, L. F. 15. November 1941. Frequency of occurrence of wars and other total quarrels. Nature, 148/37-59.

Richardson, L. F. 1960a. Statistics of Deadly Quarrels. Pittsburgh: Boxwood.

Richardson, L. F. 1960 b. Arms and Insecurity. Pittsburgh: Boxwood.

Rosecrance, R. et al. 1974. Power, Balance of
Power and Status in Nineteenth Century International Relations. Beverly Hills, Calif.: Sage.

Rosenau, J. N. 1966. Pre-theories and theories of foreign policy. In Approaches to Comparative and International Politics, ed. R. B. Farrell. Evanston, Ill.: Northwestern Univ. Press.

Rummel, R. J. 1972. The Dimensions of Nations. Beverly Hills, Calif.: Sage.

Russett, B. M. 1974. Power and Community in World Politics. San Francisco: Freeman.

Sabrosky, A. D. 1980. Interstate alliances: their reliability and the expansion of war. In Correlates of War II: Testing Some Realpolitik Models, ed. J. D. Singer. New York: Free Press.

Secerov, S. 1919. Economic Phenomena Before and After War. London: Rutledge.

Silberner, E. 1946. The Problem of War in Nineteenth Century Economic Thought. Princeton, N. J.: Princeton Univ. Press.

Singer, J. D. October, 1961. The level-of-analysis problem in international relations. World Politics, 14/1: 77-92.

Singer, J.D. 1970. The outcome of arms races: A policy problem and a research approach. Proceedings of the International Peace Research Association, Third General Conference, 2: 137-46.

Singer, J. D. 1971. A General Systems Taxonomy for Political Science. Morristown, N. J.: General Learning Press.

Singer, J. D. 1976. The correlates of war project: Continuity, diversity and convergence. In Quantitative International Politics: An Appraisal, eds. F. Hoole and D. Zinnes, pp. 21-66. New York: Praeger.

Singer, J. D. ed. 1979. Correlates of War I: Research Origins and Rationale. New York: Free Press.

Singer, J.D. ed. 1979. Explaining War. Beverly Hills, Calif: Sage.

Singer, J. D. 1979a. The Management of Serious International Disputes. Ann Arbor, Mich.: University of Michigan Department of Political Science.

Singer, J. D. ed. 1980. Correlates of War II: Testing Some Realpolitik Models. New York: Free Press.

Singer, J. D., Bremer, S. A. and Stuckey, J. 1972. Capability distribution, uncertainty and major power war, 1820-1965. In Peace, War \& Numbers, ed. B. M. Russett. Beverly Hills, Calif.: Sage. 19-48.

Singer, J. D. and Bueno de Mesquita, B. 1973. Alliances, Capabilities, and War: $A$ Review and Synthesis. Political Science Annual, IV, 237-280.

Singer, J. D. and Cusack, T. 1981. Periodicity, inexorability, and steersmanship in international war. In From National Development to Global Community, R. Merritt and B. M. Russett.

Singer, J. D. and Small, M. 1968. Alliance aggregation and the onset of war, 1815-1945. In Quan- 
titative International Politics: Insights and Evidence, ed. J. D. Singer. New York: Free Press. Singer, J.D. and Small, M. 1972. The Wages of War: A Statistical Handbook, 1816-1965. New York: John Wiley.

Singer, J. D. and Wallace, M. 1970. Intergovernmental organization and the preservation of peace, 1816-1964: Some bivariate relationships. International Organization, 24/3: 520-47.

Siverson, R. and King, J. 1980. Attributes of national alliance membership and war participation, 1815-1965. American Jnl. of Political Science, 24/1: 1-15.

Skjelsbaek, K. Shared membership in intergovernmental organizations and dyadic war, 1865-1964. The United Nations: Problems \& Prospects. St. Louis, Mo: University of Missouri Center for International Studies.

Small, M. 1978. Does size make a difference? In Studien i Dansk Udenrigspolitik, eds. N. Amstrup and I. Faurby. Aarhus, Denmark: Forlaget Politika.

Small, M., Singer, J. D. Summer, 1976. The war proneness of democratic regimes. Jerusalem Journal of International Relations, 1/4: 49-69.

Sorokin, Pitrim A. 1937. Social and Cultural Dynamics: Fluctuations of Social Relationships, War and Revolution vol. 3. New York: American Book.

Starr, H. and Most, B. Sept. 1978. A return journey. Journal of Conflict Resolution, 22/3: 441-468.

Stoessinger, J. G. 1978. Why Nations Go to War. New York: St. Martins.

Stoll, R. and Champion, M. November 1977. Predicting the escalation of serious disputes to international war: some preliminary findings. Philadelphia, Pa.: North American Peace Science Conference. Philadelphia.

Sullivan, M. 1976. International Relations: Theories and Evidence. Englewood Cliffs, N. J.: PrenticeHall.

Sullivan, M. 1978. The Causes of War: An Evaluation of the State of Theory. Tucson, Arizona: Univ, of Arizona, Department of Political Science.

Urlanis, B. T. 1960. Wars and the Population of Europe. Moscow, USSR: Government Publishing. Voevodsky, J. July, 1969. Quantitative behavior of warring nations. Journal of Psychology, 72: 269-292.

Wallace, M. D. 1973. War and Rank Among Nations. Lexington, Mass.: Heath.

Wallace, M. D. 1973. Alliance polarization, crosscutting, and international war, 1815-1964. Journal of Conflict Resolution, 17: 4.

Wallace, M. 1979. The role of arms races in the escalation of disputes into war: Some new evidence. Journal of Conflict Resolution, 23/1: 3-16.

Wallensteen, P. 1973. Structure and War. Stockholm, Sweden: Roben and Sjogren.

Wayman, F. 1981. Bipolarity, multipolarity and the threat of war. In Power, Pacts, and War, ed. N.N. Sabrosky. Boulder, Colo: Greenwood Press.

Weede, E. 1970. Conflict behavior of nation states. Journal of Peace Research, 3: 229-236.

Weede, E. Sept. 1976. Overwhelming preponderance as a pacifying condition among contiguous Asian dyads, 1950-1969. Journal of Conflict Resolution, 20/3: 395-412.

Weiss, H. K. 1963. Stochastic models for the duration and magnitude of a deadly quarrel. Operations Research, 11/1: 101-121.

Wesley, J. P. 1969. Frequency of wars and geographic opportunity. In Theory \& Research on the Causes of War, ed. D. G. Pruitt, R. C. Snyder.

White, R. K. 1968. Nobody Wanted War. Garden City, N. Y.: Doubleday.

Wilkenfeld, J. 1973. Domestic and foreign conflict. In Conflict Behavior and Linkage Politics, ed. J. Wilkenfeld, pp. 107-123. New York: Mckay.

Wilkinson, D. 1980. Deadly Quarrels. Berkeley, Calif.: University of California Press.

Wright, Q. 1942. A Study of War, 2 vols. Chicago: University of Chicago. Revised edition, 1965.

Wright, Q. 1965. The escalation of international conflicts. Journal of Conflict Resolution, 9/4: 434-449.

Zinnes, D. 1980a. Empirical evidence on the outbreak of international violence. In Handbook of Political Conflict, ed. T. Gurr. New York: Free Press.

Zinnes, D. 1980 b. 'Three Puzzles in Search of a Researcher.' Bloomington, Indiana, mimeo. 